\title{
Design and Structural Mechanics of a Modified Wood - Composite Integrated Propeller Blade
}

\author{
Sasidhar Jangam ${ }^{1, *}$, SagarVerma ${ }^{1}$, Ramesha $\mathrm{K}^{1}$ \\ Department of Mechanical and Automobile Engineering, \\ School of Engineering and Technology, CHRIST (Deemed to be University), Bangalore- \\ 560074, India \\ sasidhar.jangamechristuniveristy.in
}

\begin{abstract}
Aircraft Propellers are the key components of turboprop type engines which are used for thrust generation for the aircraft. Metallic propellers which are in use for long time are being replaced by composite type equivalent propeller due to their high specific strength and modulus. Composite material is used in combination with engineered wooden core offers refined dynamic characteristics with enhanced damping as well as greater stiffness Better damping characteristics reduces the vibrations due to external excitation sources resulting in higher fatigue life. In this study, effort will be made to design and analyze a composite bladed propeller for a typical light transport aircraft. Scope of the work in this project includes design, modeling and detailed finite element analysis of an integrated composite - engineered wood propeller blade. The structural analysis includes static structural and modal analysis for induced stresses, deformations, its natural frequencies and associated mode shapes.
\end{abstract}

Keywords:Wooden Composites, Propeller Design, finite element analysis, enhanced damping.

\section{Introduction}

With the beginning of $20^{\text {th }}$ century, aircraft propellers have played a significance role in the aviation industry after it was invented by Robert Hartzell on implementing it in the first aircraft 'Wright Flyer'. Till this date, the propellers are in use for efficient flight propulsion for multiple requirements. The design of propellers have been improved technologically in terms of structural, aerodynamics, positioning and in combination aspects along with various value addition, in essence, variable pitch, feathering and reversible pitch mechanism and these optimizations have enabled us to fly aerial vehicles ranging from a wide variety of aircraft which includes light transport aircraft for acrobatic maneuvering as well as multi-role heavy military planes for covering greater distances for bulk transport. 
The blade structure and aerodynamics are the critical parameters for any aircraft [1], in our research these parameters are considered for the purpose of design initiation. Design aspects of various composite structures and wind turbine blades have been observed [2-3] which are used for CAD modeling of the propeller blade carried out in this research. Finite element analysis of certain wind turbine blades, propellers and correlative composite structures are considered in this study with the similar structural geometry point of view [4-5]. The experimental study done on the composite structure which is used to understand the structural behaviour[6] has been considered to learn the vibrational behaviour of a wind turbine blade and for undertaking the computational modal analysis of Propeller blade [7] has been taken as it depicts the process of resulting the natural frequencies of a wing structure in pre-stressed conditions. This study focuses on the design of propeller blade for the purpose of structural and modal feasibility for the application to a light transport aircraft using computational finite element analysis

\subsection{Basic Principle}

According to Mohamed A. FouadKandil, during the rotation of Propeller blade around its axis, a pressure difference is created between both the surfaces of its blade due to asymmetrical airfoil cross section which moves the blade towards the higher pressure region which makes the aircraft move forward. The airfoil structure of the wings of an aircraft helps in attaining height. Thus, bringing the aircraft in motion for the purpose of flight.

\subsection{Problem Statement}

In the current scenario for the application of short-haul aircrafts, most of the Propellers are constructed using aluminum alloys in the blade geometry bearing most of the structural load occurringwhile in operation. Not much research has been done on this type of blade as the wooden Propeller blades were used during the II $^{\text {nd }}$ world war but were discontinued due to the emergence of metallic alloy counter parts in the Market as they offer high specific-strength.

Using metals induce large vibrations in operation which degrades the flight safety of an aircraft. Aluminum alloys are in use for the construction of propeller in an aircraft as they offer high stiffness. But after the introduction of composite technology, aviation industry has turned over from metallic to various composite materials as seen in Jane's All of the World's Aircraft [8]. This is due to the fact that using composites for making the structure has brought down the overall weight* of an aircraft resulting in increased maximum take-off weight with greater directional stiffness. Using this construction of propeller blade helps in making the power plant of the aircraft becomes lighter along with reduction of damage to the aircraft improving the technological and human safety.

A natural composite blade is constructed with integrated composite with natural and engineered aerospace-grade Wooden materials. The combination of materials in this blade is of a core and a skin member where the core acts as a greater strength 
bearing member whereas at the skin, a specific number of lay-up of composite fabrics is done to provide protection to the core.The construction of design of a natural composite Propeller blade and it respective structural analysis where computational static structural and modal analysis is discussed in this paper.

\section{$2 \quad$ Material Selection}

From Fred E. Weick, the Schwarz process of construction of propeller blade is used for modelling the core of the propeller blade. Compressed Sitka spruce wood (PiceaSitchensis) or CSSW as well as Compreg Spruce wood or CSW are used for the wooden core material. Unidirectional Glass Fiber Reinforced Polymer (GFRP) is considered for skin material. Compreg is a process in which a wooden piece is treated with phenolic resin to obtain greater strength which makes it applicable for the use of a structural member in the aerospace sector. The wooden piece kept under high pressure and temperature with high compressive load whilst under impregnation of Phenol Formaldehyde resin. After treatment, the wood is engineered into double the density of its Natural counterpart which offers stiffness matching to the aerospace alloys. Various impregnated wooden pieces are stacked and are made into laminations by compressing them in high temperature which liquifies the resin which acts as an adhesive for joining each wooden piece over the other.Compressed Sitka Spruce is used as it provides lighter weight as well as good damping characteristics. Provision of GFRP is done as this type of skin material will resist the change in moisture content of the blade core.

The properties of each material used in this research are standard properties.

\section{$3 \quad$ Methodology}

Any computational finite element analysis (FEA) is generally composed of preprocessing, processing, and post-processing. In the pre-processing the geometry is modelled, the mesh is generated, and the boundary conditions are defined. In the processing, the solution is computed while in the post-processing results are obtained.

\subsection{Design Procedure}

We have used a composite blade with a length of $1200 \mathrm{~mm}$ which is suitable for the application of Light Transport Aircraft. To model the surface of propeller blade so as to use for generating various other components, following illustration depicts the cross-sectional dimensions provided. 
Fig. 1: Cross-sections for generating CAD Model

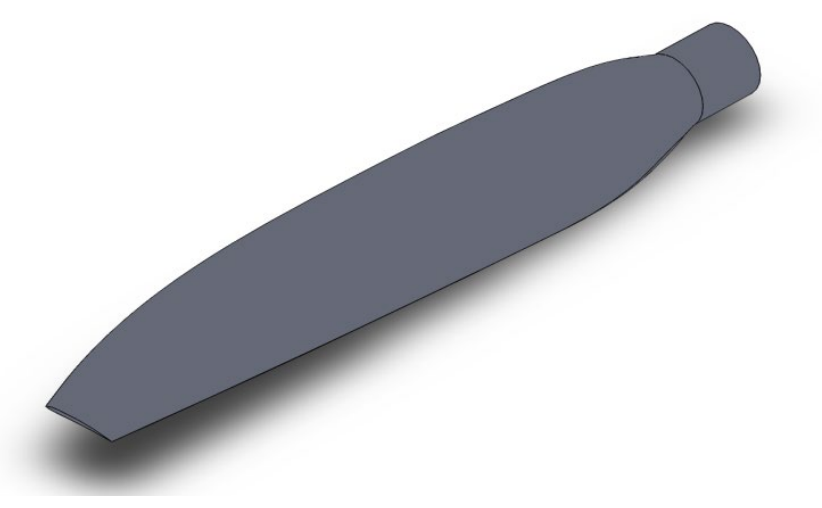

Fig. 2: CAD model of Propeller Blade

With the provision of various cross-sections, CAD model of the propeller blade has been generated which is depicted in the following figure. Enhanced damping characteristics will be observed as the core of the blade consists of engineered wooden material (CSW and CSSW) and bears the structural load when the blade is in operation. [9]

The Design of each component of this type of blade is described as below:

I. Core

The major structural member of the blade is the core which comprises of almost all the volume inside the blade and it has a significant advantage on the other types of propellers developed. Using Schwarz process of propeller blade construction, a specific number of slices (in this case, 15 slices) of CBW are connected to the slices of 
CSSW using scarf joint. This procedure of construction of propeller blade is considered for obtaining decreased operational vibrations with feasible structural stiffness. Using the CBW at the root side for strength and CSSW at majority of the portion towards the tip to keep the structure light weight. Whereas, the scarf joint provides better structural strength as compared to other types of joints (lap, butt \& finger joint). As per Ref. [2], greater scarf length comprised for greater structural strength, therefore, for initiation of research, we consider the scarf length from $20 \%$ to $50 \%$ of the total length of blade.

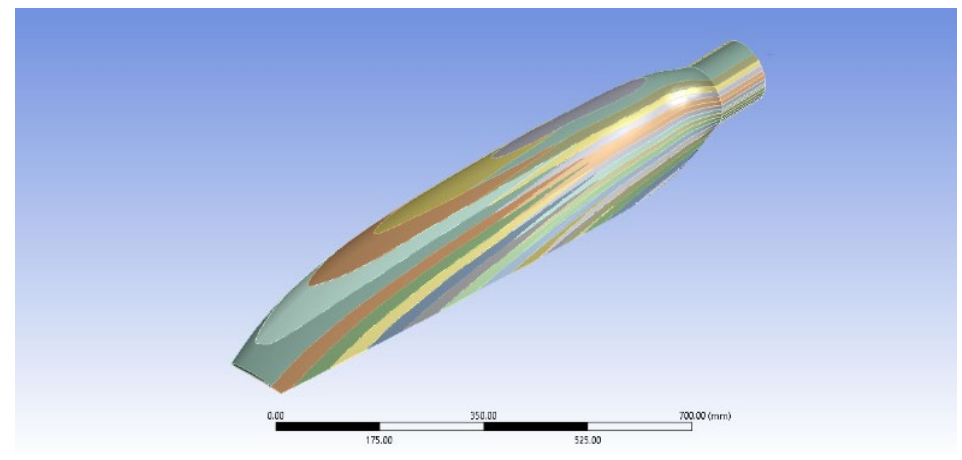

Fig. 3: Core Geometry

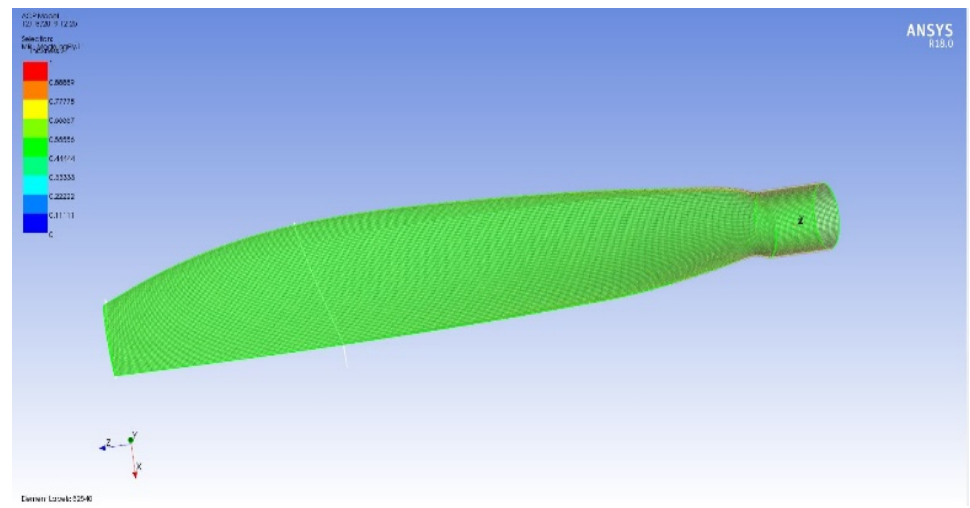




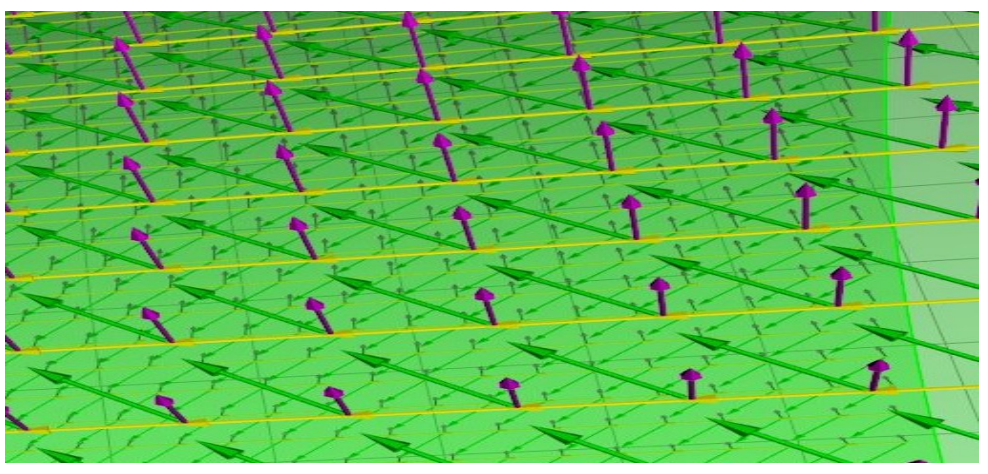

Fig. 4: Skin fiber direction

\section{Skin}

Using ANSYS ACP, this component of the blade has been modelled of three layers of UD GFRP material each having fiber orientation with reference as the blade length in the directions

$$
-45^{\circ} / 45^{\circ} / 0^{\circ}
$$

Where the innermost layer has the orientation of fiber as $-45^{\circ}$. The lay-up is done over the wooden core. The importance of having the skin is to provide protection in terms of moisture as well as keeping the blade compact. The figure below depicts the outermost layer of UD GFRP having $-45^{\circ}$ with the reference depicted with dark green arrow whereas yellow and purple arrows in the illustration depict reference and lay-up direction respectively. Both the components are integrated and assembled in succeeding static structural and modal analysis systems according to the definition of global Coordinate System

\section{Pre-processing:}

\section{Meshing}

Meshing of core has been provided with refinement and contact control to observe feasible and maximally fine mesh with element quality approximate to 0.6. 


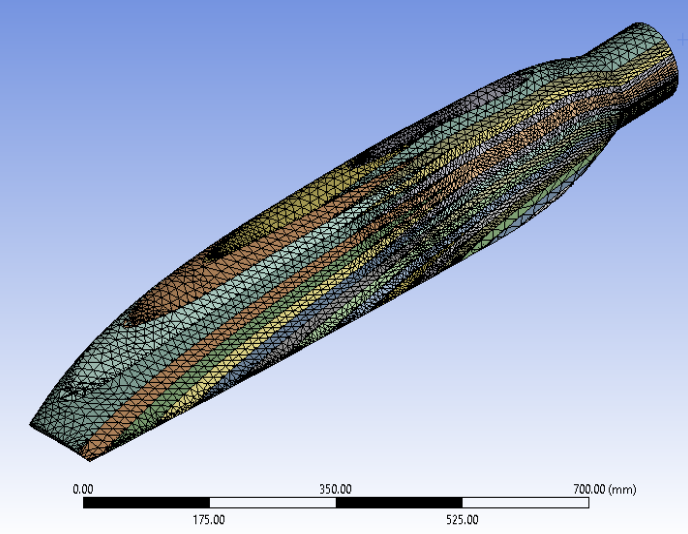

Fig. 5: Meshed Geometry of Core

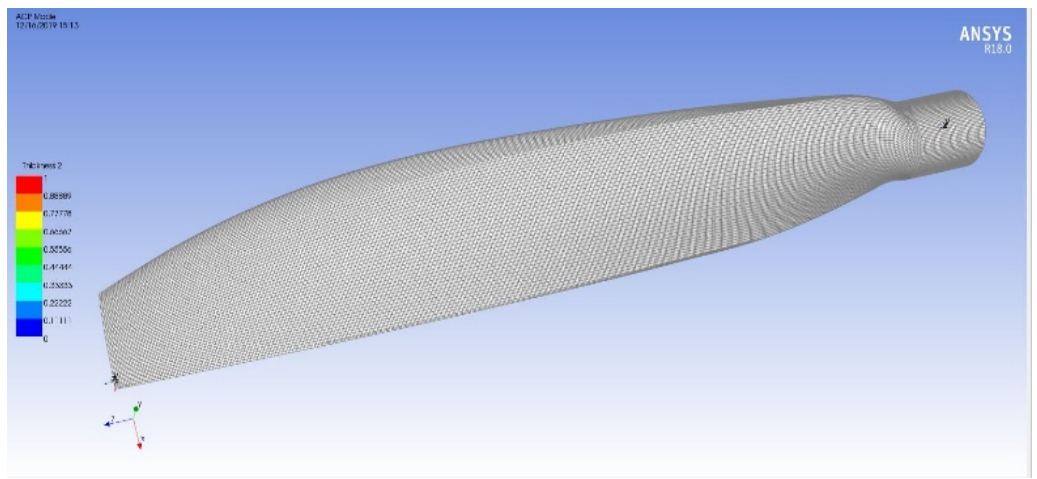

Fig. 6: Meshed Geometry of Skin

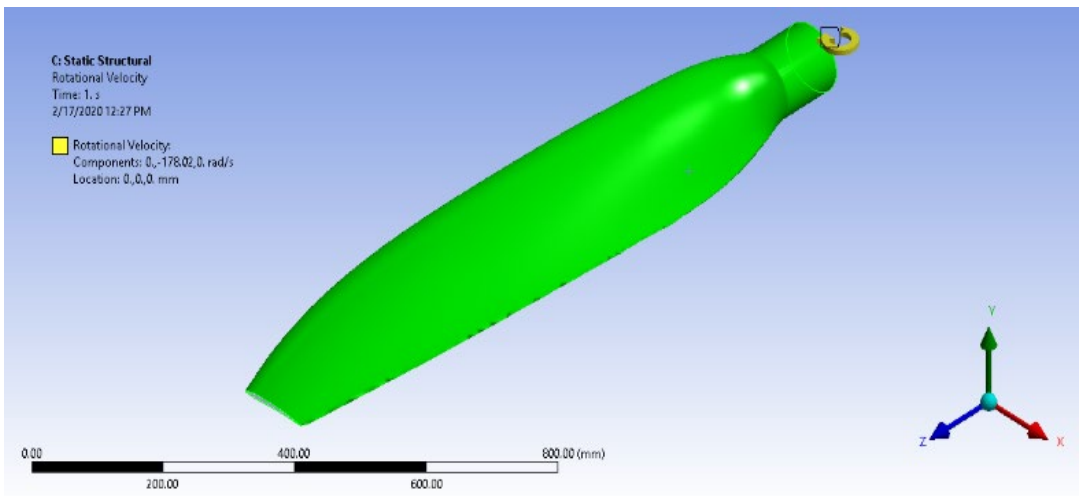


Fig.7: Blade with Rotational Velocity input

Skin has been provided with hexagonal type mesh with significant number of elements to support the composite structure in composite modeling in ANSYS ACP to obtain a structurally possible solid structure of composite material as it poses a challenge in respect to composite modeling. Using the above criteria, we proceed towards the next stage of pre-processing, in essence, the imposition of conditions of the respective model [10] to be analyzed structurally as well as in terms of natural frequency.

\section{Loads and Constraints:}

- The complete blade is given a rotational velocity of 1700 RPM keeping the leading edge of blade ahead. This rotation is the highest value for the blade in operation.

- The root end surface is given a fixed support to obtain the stresses induced due to rotation and deformation.

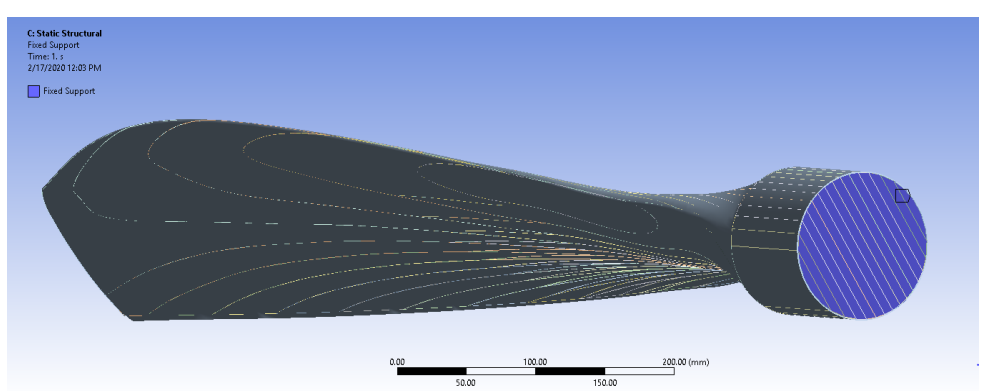

Fig.8: Fixed Support

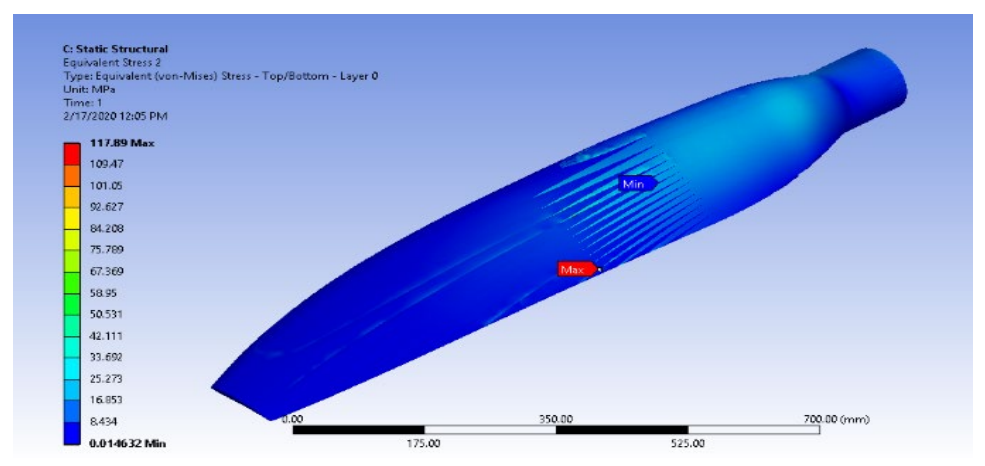

Fig. 9: Equivalent Stress in Core $\left(\sigma_{\max .}=117.89 \mathrm{MPa}\right)$ 


\section{Analysis Systems:}

\section{Static Structural}

Equivalent (Von-Mises) Stresses for both components of the blade i.e. core and skin as well as total deformation is provided as a solution output to static structural analysis.

Modal

The finite element modal analysis is made to obtain modal parameters and the natural frequency spectrum of blade [7]. With the constraints of static structural analysis kept as pre-stressed conditions, first three modes (I.e. $\mathrm{I}^{\text {st }}$ Bending, $\mathrm{II}^{\text {nd }}$ Bending and $\mathrm{I}^{\mathrm{st}}$ Twisting) are given as an input to check the natural frequency of the blade. These modes are selected to check resonance of blade with the frequency while the blade is in operation. As the blade rotates at $1700 \mathrm{rpm}$, in terms of frequency it can be derived as follows:

$$
v_{0}=\frac{1700}{60} \mathrm{~Hz} \therefore v_{0} \cong 28.33 \mathrm{~Hz}
$$

We will compare the above frequency with the natural frequency of the blade which will be observed after modal analysis under pre-stressed conditions.

\section{$4 \quad$ Results and Discussion}

The induced stresses in the blade for each component are depicted as below: 


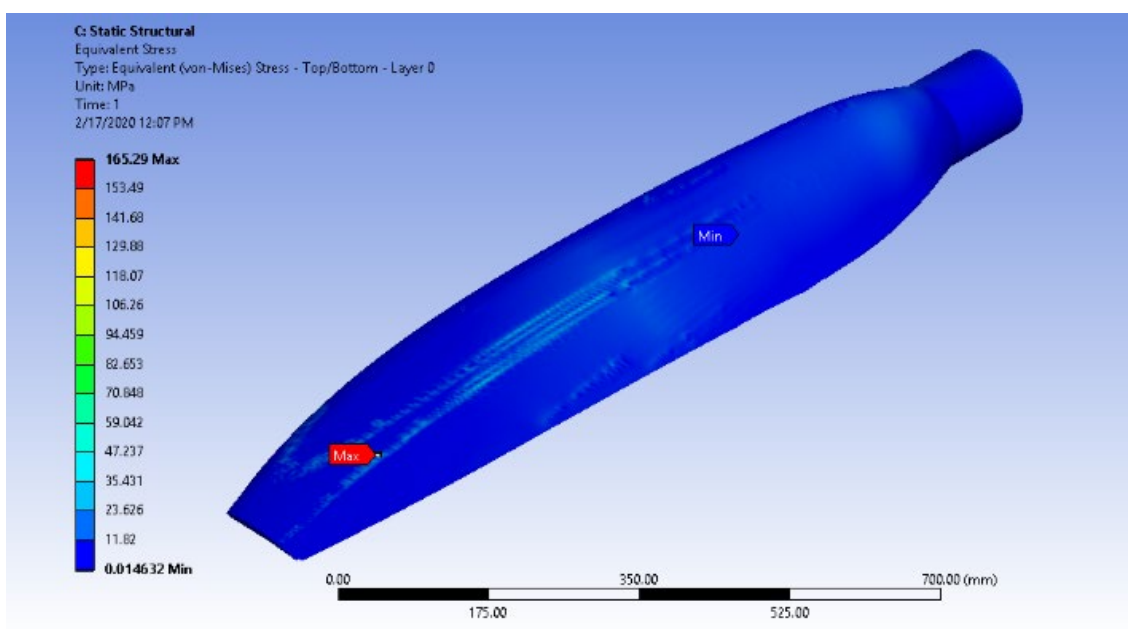

Fig. 10: Equivalent Stresses in Skin $\left(\sigma_{\max .}=165.29 \mathrm{MPa}\right)$

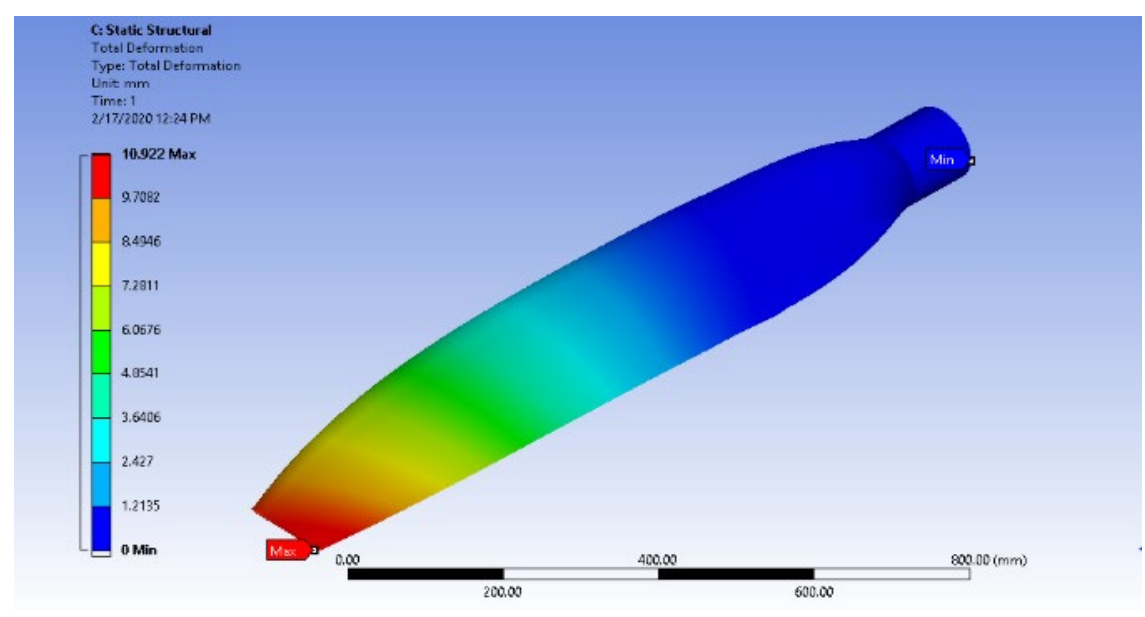

Fig.11: Total Deformation (Max. at tip - $10.922 \mathrm{~mm}$ ) 


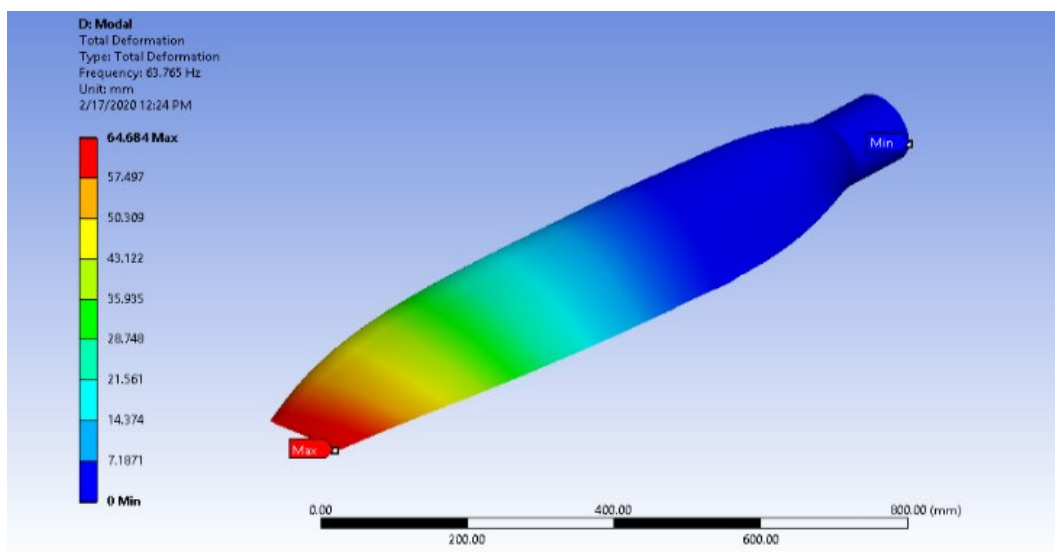

Fig.12: $1^{\text {st }}$ Mode Shape ( $1^{\text {st }}$ Bending $) 63.765 ~ H z$

Following are the natural frequencies observed in the blade with the associated mode shapes.

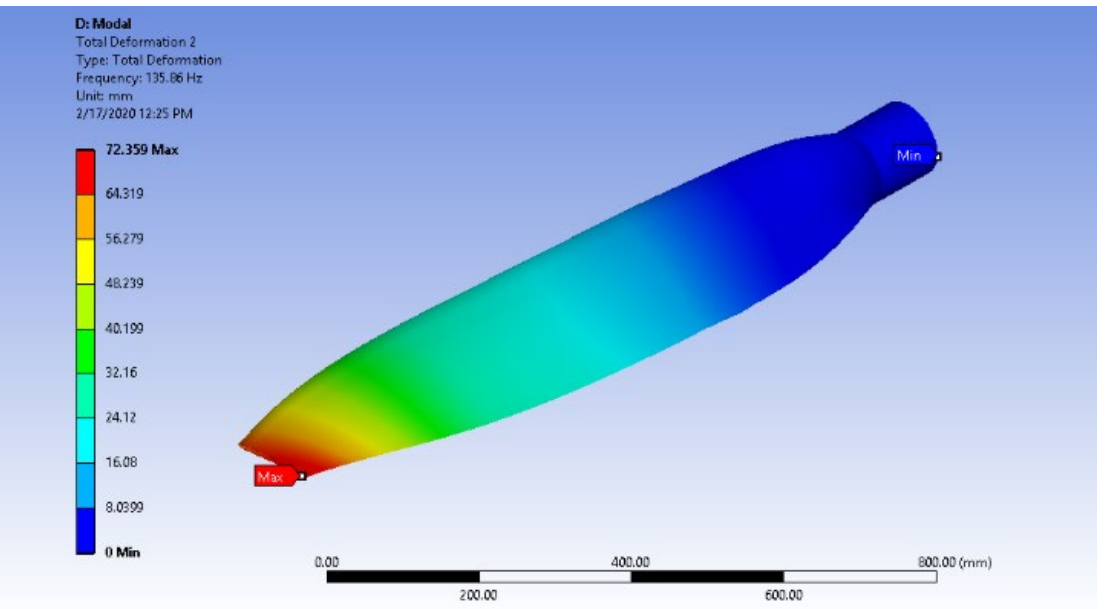

Fig.13: $2^{\text {nd }}$ Mode Shape ( $2^{\text {nd }}$ Bending $) 136.86 \mathrm{~Hz}$ 


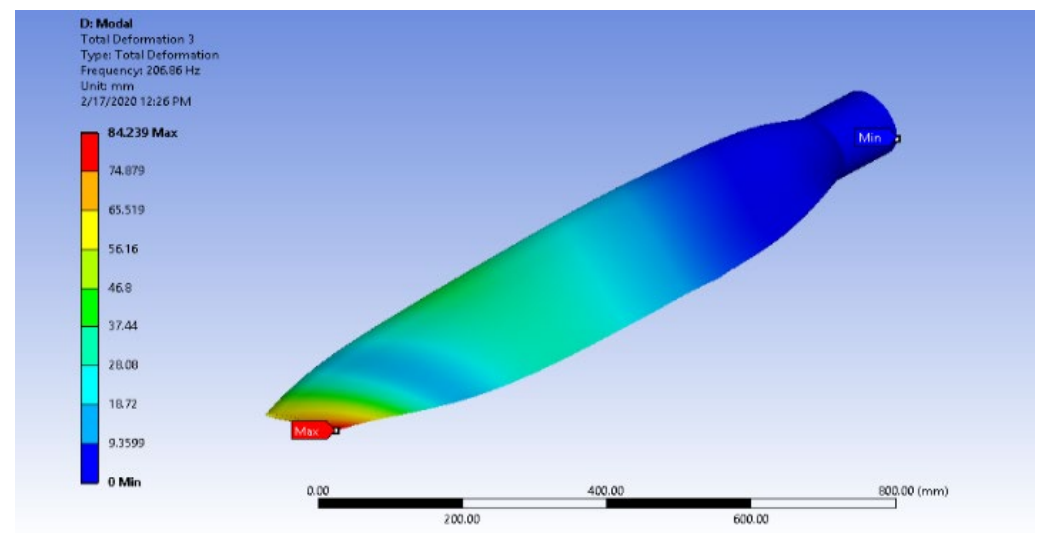

Fig.14: $3^{\text {rd }}$ Mode Shape ( $1^{\text {st }}$ Twisting) $206.86 \mathrm{~Hz}$

In the above analysis results, it is observed that:

- Greater stress occurrence in the core geometry of the blade is at the end of scarf joints of each wooden laminations or slices of CSW type wood. I.e.

- Core: $\sigma_{\max }=117.89 \mathrm{MPa}$

- The stresses induced in the skin component of the blade are well within the limits.

- Skin: $\sigma_{\max .}=165.29 \mathrm{MP}$

- Also, the natural frequencies are significantly high for the application at the current RPM and are feasibly safer in terms of vibrational aspects. Various mode shapes of propeller are observed as following:

- $v_{1}=63.765 \mathrm{~Hz} v_{2}=136.86 \mathrm{Hv}_{3}=206.86 \mathrm{~Hz}$

The observed results of computational analysis of this design of propeller blade show the maximum stresses induced in the core and skin of this propeller blade design, total deformation and three modes of natural frequency of the complete structure (as mentioned above) under pre-stressed conditions for elastic region. These values indicate the structural behaviour of propeller blade in operational conditions in application to a light transport aircraft having a certain angular velocity of rotation.

\section{Conclusions}

The structural static analysis provides us with the mechanical behaviour of the respective assembly. In terms of stress concentrations, the results show that the induced stress in well within the limit of the material properties where the maximum load is observed nearer to the root where CBW material is present which can sufficiently induce the observed stresses in the core. The stresses in the skin is also in a safe range. Observed Mode Shapes for this natural composite blade in operation concludes that as operating frequency is way lesser as compared to all the three modes of natural frequency. I.ev $v_{0} \ll v_{1}, v_{2}, v_{3}$. Therefore, the blade is sufficiently stiff in terms of damping and relatively safer for operation in terms of vibrational aspect due to which 
the use of composite propeller has a greater significance for the design of propeller blade. The blade under operation can be described as a similar to a cantilever beam under uniformly distributed load as the deflection in the blade is caused due to the eccentricity of the CG (Centre of Gravity) in the blade. It has been observed that with the combination of composite materials with engineered wood can act as structural components of the propeller blade with extreme damping characteristics resulting in better feasibility for aerospace applications.

\section{References}

[1] M. F. Rabbey, A. M. Rumi, F. H. Nuri, H. M. Monerujjaman, and M. M. Hassan., 2014. Structural deformation and stress analysis of aircraft wing by finite element method. Adv. Mater. Res., 906(1), pp. 318-322.

[2] Cox, K. and Echtermeyer, A., 2012. Structural design and analysis of a 10MW wind turbine blade. Energy Procedia, 24(1876), pp. 194-201.

[3] G. Fontecha Dulcey, X. Fischer, P. Joyot, and G. Fadel., 2018. Support for Decision Making in Design of Composite Laminated Structures. Part 2: Parametric ModelBased Optimization. Appl. Compos. Mater., 26(2), pp. 643-662.

[4] M. Tarfaoui, O. R. Shah, and M. Nachtane., 2008. Design and optimization of composite offshore wind turbine blades. J. Energy Resour. Technol., 141(5), pp. 1-12.

[5] S. Jangam, S. Raja, and B. . Maheswar Gowd., 2016. Influence of multiwall carbon nanotube alignment on vibration damping of nanocomposites. Journal of Reinforced Plastic Composites., 35(8),pp.617-627.

[6] Jangam S., Hema Devi A., Raja S., Hemachandra Reddy K., Vijay Kumar G. 2018. The Tensile Fatigue Behaviour of Aligned MWNT/Epoxy Nanocomposites. In: Seetharamu S., Rao K., Khare R. (eds) Proceedings of Fatigue, Durability and Fracture Mechanics. Lecture Notes in Mechanical Engineering. Springer, Singapore., pp. 351359.

[7] S. Jangam, K. H. Reddy, and S. Raja., 2018. Fabrication \& Characterization of Hybrid fibers and Hybrid Fiber reinforced composites - A Novel Approach. Mater. Today Proc., 5(1), Part 3, pp. 2795-2802.

[8] S. Jangam, S. Raja, and K. H. Reddy., 2017. Effect of multiwalled carbon nanotube alignment on the tensile fatigue behavior of nanocomposites. J. Compos. Mater., 52(17), pp. 2365-2374. 